\title{
Quantitative determination of trypsin inhibitor as a breeding marker in maize varieties with different resistance to fungal diseases
}

\author{
Galina V. Shekhvatova ${ }^{1^{*}}$, Viktor V. Ashin ${ }^{2}$, \\ Elena F. Sotchenko ${ }^{3}$ \\ ${ }^{1}$ Scientific Research Production Company Gamma, \\ Pushchino, Russian Federation \\ ${ }^{2}$ Skryabin Institute of Biochemistry and Physiology of Microorganisms RAS, \\ Pushchino, Russian Federation \\ ${ }^{3}$ Russian Research Institute of Maize, Pyatigorsk, Russian Federation \\ *Correspondent author: shgal06@gmail.com
}

\begin{abstract}
Determination of plant resistance to fungal pathogens is an important breeding component. Thus, the study of protein profiles from corn kernels (13 genotypes) revealed a constitutively pronounced $14 \mathrm{kDa}$ protein, trypsin inhibitor (TI), which is present at a relatively high level of concentration in seven Aspergillus flavus - resistant maize lines, but at low concentrations or is absent in six sensitive lines. The $14 \mathrm{kDa}$ trypsin inhibitor (TI) also showed antifungal activity against other mycotoxicogenic species. In this regard, the task was to determine the content of TI in varieties of maize with known properties, resistance, or sensitivity to such fungal pathogens of maize as head smut, common smut, and Fusarium stalk rot. According to the data obtained, the content of TI varies in different varieties and can vary by 4 times. However, in disease-resistant varieties its content is increased, which may be the primary marker of resistance of the variety to fungal pathogens.
\end{abstract}

Key words: maize, trypsin inhibitor, trypsin-agarose, fungal pathogens, head smut, common smut, Fusarium stalk rot

\section{Article history:}

Received: 9 July 2019. Accepted: 04 November 2019

\section{For citation:}

Shekhvatova GV, Ashin VV, Sotchenko EF. Quantitative determination of trypsin inhibitor as a breeding marker in maize varieties with different resistance to fungal diseases. RUDN Journal of Agronomy and Animal Industries. 2019; 14(4):390 - 402. doi: 10.22363/2312-797X-2019-14-4-390-402

Шехватова Г.В., Ашин В.В., Сотченко Е.Ф., 2019.

(c) () This work is licensed under a Creative Commons Attribution 4.0 International License https://creativecommons.org/licenses/by/4.0/ 


\title{
Определение количества ингибитора трипсина как маркера селекции сортов кукурузы с различной устойчивостью к грибковым заболеваниям
}

\author{
Г.В. Шехватова ${ }^{1 *}$, В.В. Ашин ${ }^{2}$, Е.Ф. Сотченко ${ }^{3}$ \\ ${ }^{1}$ Научно-производственная фирма «Гамма», \\ Пущино, Российская Федерациия \\ ${ }^{2}$ Институт биохимии и физиологии микроорганизмов им. Г.К. Скрябина РАН, \\ Пущино, Российская Федерация \\ ${ }^{3}$ Всероссийский научно-исследовательский институт кукурузы, \\ Пятигорск, Российская Федеращия \\ *shgal06@gmail.com
}

\begin{abstract}
Аннотация. Устойчивость растений к патогенным грибам является важной селекционной составляющей. Механизмы устойчивости очень разнообразны и могут включать в себя взаимодействия ферментов и их ингибиторов. В связи с этим проведено сравнение содержания ингибитора трипсина (ИТ), как возможного маркера селекции, в зрелых зернах сортов кукурузы с известной устойчивостью к пыльной головне, пузырчатой головне и стеблевой гнили. В качестве изучаемых объектов взяты 6 устойчивых и 12 чувствительных сортов. Для гарантированного извлечения из экстрактов молотых зерен кукурузы только ИТ применялась колоночная аффинная хроматография на трипсин-агарозе в аналитическом варианте. В результате выяснилось, что содержание ИТ варьирует внутри обеих групп сортов кукурузы: в устойчивой группе - максимум 347 и минимум 162 мкг/г, в чувствительной группе - максимум 200 и минимум 84 мкг/г. Соотношения максимумов к минимумам $(2,3)$ одинаковы в обеих группах, но максимальное и минимальное содержание почти в два раза выше в группе устойчивых сортов кукурузы. В среднем в устойчивых сортах кукурузы содержание ИТ выше в 1,7 раза. Полученные данные подтверждают возможность использования содержащегося в кукурузных зернах ИТ в качестве маркера при выведении новых сортов кукурузы, устойчивых к пыльной головне, пузырчатой головне и стеблевой гнили.
\end{abstract}

Ключевые слова: кукуруза, ингибитор трипсина, трипсин-агароза, грибковые патогены, пыльная головня, пузырчатая головня, стеблевые гнили.

\section{История статьи:}

Поступила в редакцию 9 июля 2019 г. Принята к публикации 04 ноября 2019 г.

\section{Для цитирования:}

Шехватова Г.В., Ашин В.В., Сотченко Е.Ф. Определение количества ингибитора трипсина как маркера селекции сортов кукурузы с различной устойчивостью к грибковым заболеваниям // Вестник Российского университета дружбы народов. Серия: Агрономия и животноводство. 2019. T. 14. № 4. C. 390 - 402. doi: 10.22363/2312-797X-2019-14-4-390-402

\section{Introduction}

Plants are exposed to a large number of infectious pathogenic fungi. For maize, common smut, head smut, stem rot, fusarium disease are the most common fungal pathogens in the Russian Federation. While in countries with a hot and arid climate, pathogens of the genus Aspergillus are most common, the effects of which are most fully studied.

Thus, a study of protein profiles from maize grains (13 genotypes) revealed a constitutively expressed $14 \mathrm{kDa}$ protein, a trypsin inhibitor (TI), which was present in relatively high concentrations in seven maize A. flavus resistant lines, but in low concen- 
trations or was absent altogether in six sensitive lines [1]. $14 \mathrm{kDa}$ TI also showed antifungal activity against other mycotoxicogenic species [2].

Although plants do not have an immune system, they use protective mechanisms, including the synthesis of low molecular weight compounds, proteins and peptides with antifungal activity. To date, 13 classes of antifungal proteins are known, among them PR-1 proteins, 1,3- $\beta$-glucanases, chitinases, chitin-binding proteins, thaumatin-like proteins, defensins, cyclophilin-like proteins, proteinase inhibitors and other proteins [3].

Proteinase inhibitors are an integral part of protection system against pests and diseases [4]. It was shown that pathogenic fungi Fusarium and Helminthosporium secrete enzymes into the environment that break down protein and synthetic substrates. Different types of fungi are characterized by unequal activity of extracellular proteinases. The high content of extracellular proteinase inhibitors of the pathogenic fungi Fusarium and Helminthosporium in the seeds of pea, buckwheat, and corn can be one of the important factors ensuring the resistance of these crops to root rot [5].

Similarly, TI content of $14 \mathrm{kDa}$ in maize seeds was shown to correlate with resistance to A. flavus disease [3] and, therefore, aflatoxin accumulation.

In addition to trypsin-inhibiting activity, TI from $14 \mathrm{kDa}$ maize was shown to have alpha-amylase activity, and, when added to the nutrient medium, it suppressed growth of conidia and growth of phytopathogen hyphae Aspergillus flavus, Asp. paprasiticus, $F$. moniliforme, and also showed antifungal activity against other mycotoxicogenic species $[2,6]$.

We held experiments to study TI content of $14 \mathrm{kDa}$ in maize samples with known properties, resistance or sensitivity to fungal pathogens, such as head smut (pathogen Sphacelotheca reiliana), common smut (pathogen - Ustilago maydis, U. zeae) and stalk rot of maize (pathogen — Fusarium moniliforme fungus).

\section{Materials and methods}

Object of study. Maize varieties with known properties of resistance (sensitivity) to fungal pathogens (head smut, common smut and stalk rot) were provided from Russian Research Institute of Maize in Pyatigorsk. Six varieties resistant to fungal infections and 12 varieties sensitive to fungal pathogens were investigated.

Sample preparation. The seeds were ground, each maize sample (10 g) was extracted with $20 \mathrm{ml}$ of a $0.2 \mathrm{M} \mathrm{NaCl}$ solution, stirred for 2.5 hours, then filtered, and approximately $15 \mathrm{ml}$ of extract was obtained. To each sample, $6 \mathrm{~g}$ of ammonium sulfate (60\% concentration) was added, left in the refrigerator for 18 hours overnight. Then it was centrifuged for 10 minutes, the precipitate was dissolved in $5 \mathrm{ml}$ of buffer $(20 \mathrm{mM}$ Tris- $\mathrm{HCl}, 0.15 \mathrm{M} \mathrm{NaCl}, \mathrm{pH} 6,8)$ and used for application on trypsin agarose or on HPLC.

Trypsin agarose affinity chromatography. An affinity sorbent, trypsin agarose, was chosen as the isolation method [7]. Trypsin agarose was obtained by immobilizing TPCK trypsin on BrCN agarose.

To quantify the method, a standard sample of $14 \mathrm{kDI}$ TI, $200 \mu \mathrm{g}$ in $1 \mathrm{ml}$ of equilibration buffer was used.

Samples of $1.2 \mathrm{ml}$ of each extract were applied to a trypsin-agarose column $(4 \mathrm{ml})$ at a rate of $0.5 \mathrm{ml} / \mathrm{min}$. After washing with equilibration buffer $(10 \mathrm{mM}$ Tris- $\mathrm{HCl}, 0.3 \mathrm{M}$ $\mathrm{NaCl}, \mathrm{pH} 7.0$ ), an elution with $0.15 \mathrm{M}$ acetic acid was performed. 
HPLC (hydrophobic chromatography). Sample analysis was performed on an RP-304 (250×4.6) Bio Rad column. The following conditions were used: $3^{\prime}-$ $0 \% \mathrm{CH}_{3} \mathrm{CN} ; 40^{\prime}-100 \% \mathrm{CH}_{3} \mathrm{CN} ; 50$ - $100 \% \mathrm{CH}_{3} \mathrm{CN}, 65^{\prime}-0 \% \mathrm{CH}_{3} \mathrm{CN}$.

$200 \mu \mathrm{g}$ of $14 \mathrm{kDI}$ TI was previously used as a standard.

Electrophoresis in page. SDS-PAGE 15\% gel electrophoresis was used to analyze samples.

\section{Results}

6 smut-resistant maize varieties and 12 varieties susceptible to smut and stalk rot were studied. The samples of maize grains with known properties of resistance (sensitivity) to fungal pathogens were provided from Russian Research Institute of Maize in Pyatigorsk.

Peak areas obtained by trypsin-agarose chromatography were calculated by mathematical methods. The amount of $14 \mathrm{kDa}$ TI was determined on the basis of calibration; for this, a sample containing $200 \mu \mathrm{g}$ TI was used (Fig. 1).

A typical chromatography picture of extracts of maize kernels on trypsin agarose is shown in Fig. 2.

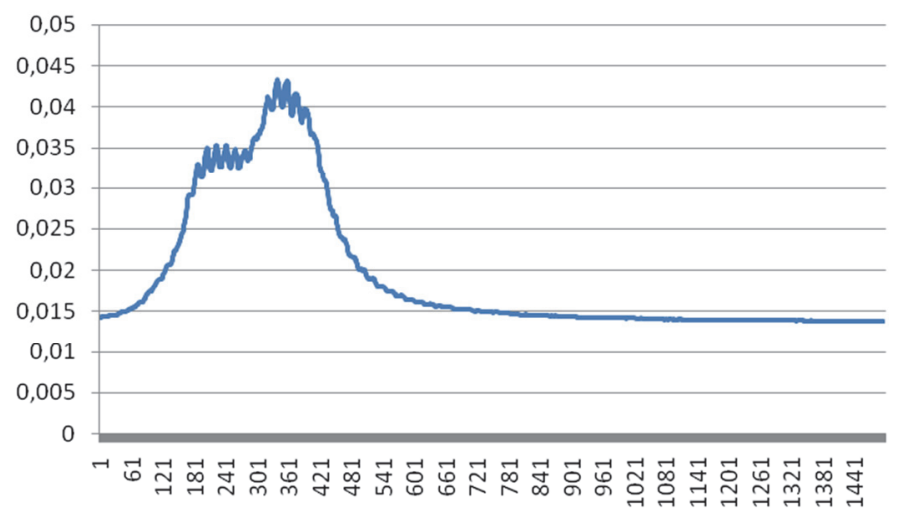

Fig. 1. Standard chromatography curve on trypsin-agarose. In this case, $200 \mu \mathrm{g}$ of $14 \mathrm{kDa}$ TI is applied for calibration

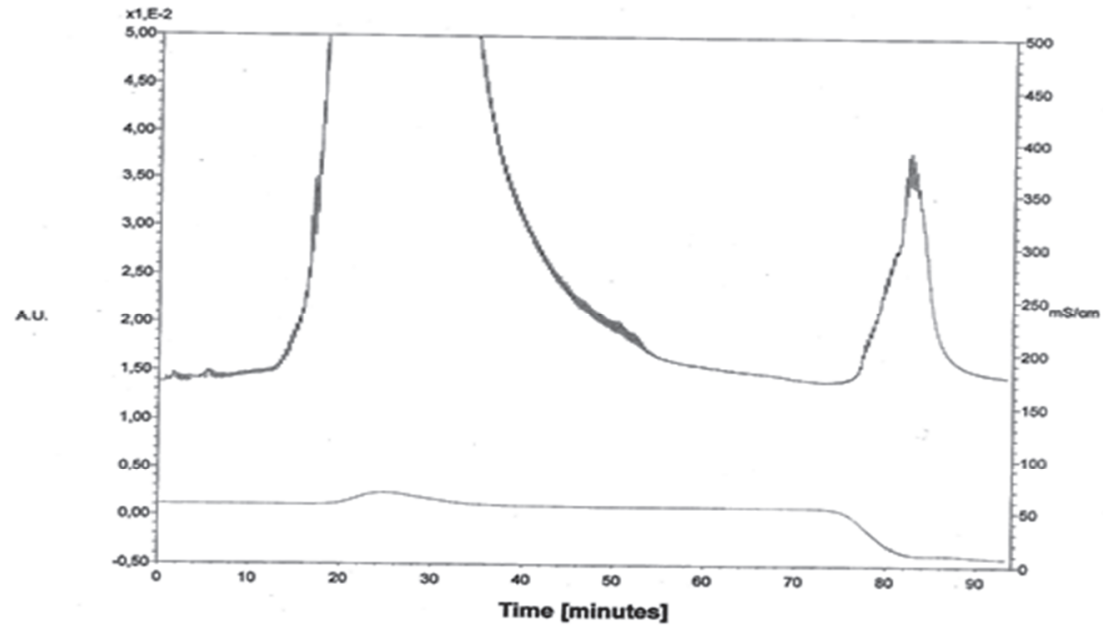

Fig. 2. Typical chromatography curve of maize grains extract on trypsin-agarose: second peak - Tl elution 


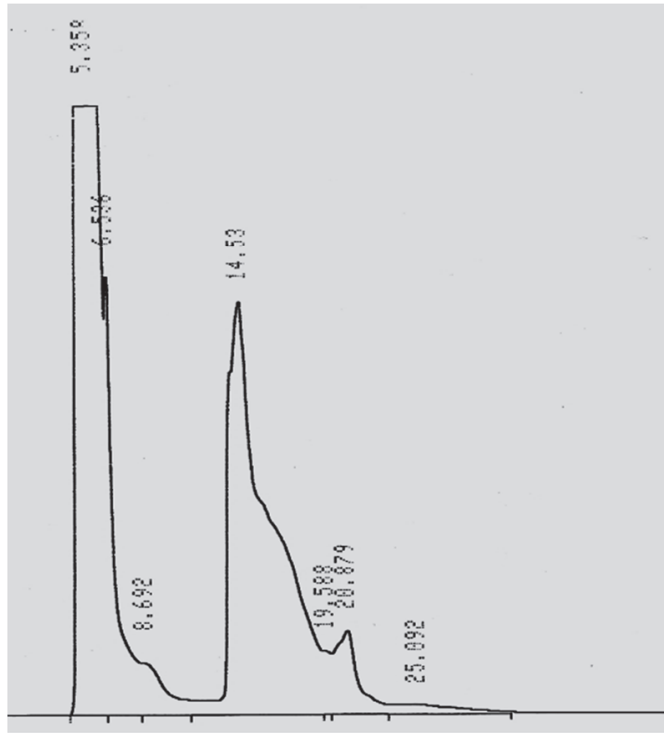

Fig. 3. Typical elution profile of maize grain extract on HPLC

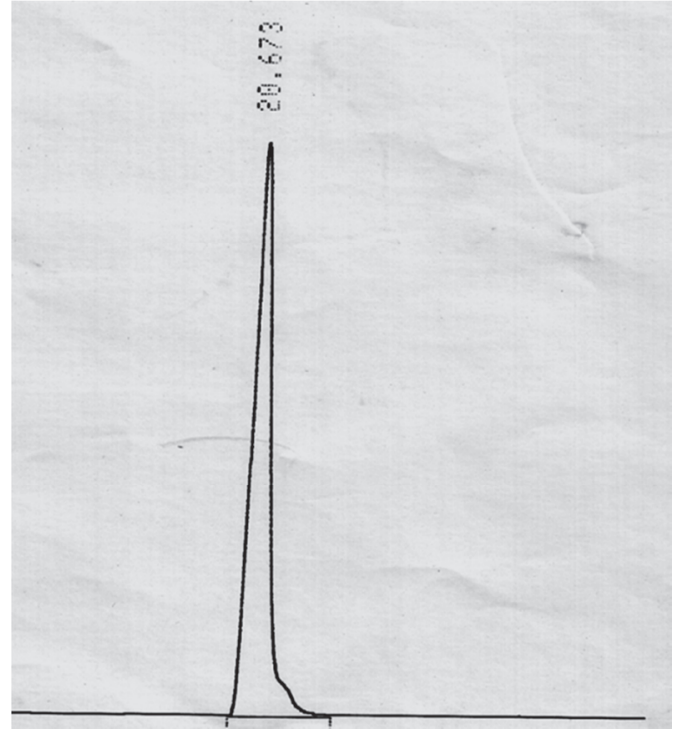

Fig. 4. $14 \mathrm{kDa}$ trypsin inhibitor as a standard in HPLC $(200 \mu \mathrm{g})$

According to HPLC, 4 extracts of different maize varieties were studied (Fig. 3, 4). The following results were obtained:

1st sample - 4.14\% $14 \mathrm{kDa}$ TI (resistant to Sphacelotheca, R);

2nd sample - $0.09 \% 14 \mathrm{kDa}$ TI (susceptible to Sphacelotheca, S);

3rd sample - 3.40\% $14 \mathrm{kDa}$ TI (resistant to Ustilago, R);

4th sample - 3.60\% $14 \mathrm{kDa}$ TI (susceptible to Ustilago, S).

Subsequently, an analysis of extracts of different varieties of maize grains was carried out ( $\mathrm{R}$ - resistant varieties, $\mathrm{S}$ - susceptible) using affinity chromatography on trypsin agarose (Table 1). An additional 18 samples were examined. A standard sample containing $200 \mu \mathrm{g}$ of $14 \mathrm{kDI}$ TI was used for calibration.

Table 1

Results of screening maize varieties by quantity of $14 \mathrm{kDa}$ trypsin inhibitor

\begin{tabular}{|c|c|l|}
\hline Elution peak area & $\begin{array}{c}\text { Calculated TI } \\
\text { per } 1 \mathrm{~g} \text { of corn grains }\end{array}$ & \multicolumn{1}{|c|}{ Resistance to fungal diseases } \\
\hline 11.3 & $290 \mathrm{mcg}$ & R Ustilago $(580 / 14)$ \\
\hline 6.85 & $174 \mathrm{mcg}$ & VR Sphacelotheca $(4716 / 11)$ \\
\hline 8.94 & $228 \mathrm{mcg}$ & R Ustilago $(3867 / 11)$ \\
\hline 13.59 & $347 \mathrm{mcg}$ & R Ustilago (3941/11) \\
\hline 6.3 & $162 \mathrm{mcg}$ & VR Sphacelotheca (1358/12) \\
\hline 10.9 & $278 \mathrm{mcg}$ & VR Sphacelotheca $(4683 / 11)$ \\
\hline 3.29 & $84 \mathrm{mcg}$ & S Ustilago, Fusarium $(2617 / 09)$ \\
\hline 4.53 & $115 \mathrm{mcg}$ & S Fusarium 2597/09 \\
\hline 3.59 & $86 \mathrm{mcg}$ & S Sphacelotheca 127272013 \\
\hline 6.35 & $162 \mathrm{mcg}$ & S Sphacelotheca $(3398 / 14)$ \\
\hline 5.83 & $149 \mathrm{mcg}$ & S Fusarium $(2613 / 09)$ \\
\hline 7.73 & $197 \mathrm{mcg}$ & S Ustilago $(2599 / 09)$ \\
\hline 7.6 & $190 \mathrm{mcg}$ & S Ustilago $(2075 / 12)$ \\
\hline 8.09 & $200 \mathrm{mcg}$ & S Ustilago $(2613 / 09)$ \\
\hline 5.8 & $140 \mathrm{mcg}$ & S Ustilago (1200/13) \\
\hline 5.5 & $132 \mathrm{mcg}$ & S Ustilago (3358/14) \\
\hline 5.7 & $138 \mathrm{mcg}$ & S Ustilago (1506/14) \\
\hline 7.7 & $190 \mathrm{mcg}$ & S Ustilago $(605 / 12)$ \\
\hline 7.83 & $200 \mathrm{mcg}$ & TI, standard sample \\
\hline
\end{tabular}




\section{Results and discussion}

Earlier [1], in the study of maize grain extracts (13 genotypes), the presence of constitutive $14 \mathrm{kDa}$ TI at a relatively high concentration level was shown in seven $A$. flavus resistant varieties of maize, but in six susceptible varieties TI was present in low concentration or was absent altogether.

The mechanism of action of TI against fungal growth may be partially due to the inhibition of fungal amylase, which restricts access of $A$. flavus to simple sugars [5], which is necessary not only for the growth of pathogenic fungi, but also for their production of toxins. TI also demonstrated antifungal activity against other mycotoxigenic species [2].

In [6], TI content was studied in different varieties of Indian maize, resistant and susceptible to A. Parasiticus, the data are shown in Table 2.

Proteomic analysis of wheat germ proteins and endosperm proteins of maize varieties resistant and susceptible to Aspergillus flavus, separated by two-dimensional electrophoresis (2 D PAGE), showed that there were 5 more constitutive marker proteins, namely — storage proteins (globulin 1 and globulin 2), proteins of late embryogenesis (LEA), proteins associated with drought (LEA3 and LEA14) or osmotic stress (WSI18 and aldose reductase) and proteins associated with heat stress (HSP16.9). Aldose reductase activity, measured in resistant and susceptible genotypes before and after infection, indicates the importance of constitutive levels of this enzyme for resistance [7].

Table 2

Trypsin inhibitor concentration in Indian maize varieties [6]

\begin{tabular}{|c|c|c|}
\hline Variety & $\begin{array}{l}\text { Trypsin inhibitor concentration in } \\
\text { Indian maize varieties }\end{array}$ & $\begin{array}{c}\text { Response } \\
\text { to } A \text {. parasiticus infections }\end{array}$ \\
\hline LM-6 & 242.2 & \multirow{4}{*}{ Resistant } \\
\hline $\mathrm{P}(\mathrm{Y}) \mathrm{S}-8-185-6-\mathrm{B} 8 \mathrm{~B}$ & 258 & \\
\hline GY-37-1-328 & 420 & \\
\hline CML-142 & $421-2$ & \\
\hline CML-176 & 90 & \multirow{6}{*}{ Susceptible } \\
\hline Pob-24-FSRS-C-1 & 90 & \\
\hline Hyd-9745 & 132 & \\
\hline Maduri & 134 & \\
\hline CML-185 & 158 & \\
\hline CML-430 & 188 & \\
\hline CML-291 & 266 & \multirow{10}{*}{ Moderately susceptible } \\
\hline CML-161 & 36 & \\
\hline African tail & 130 & \\
\hline CML-150 & 130 & \\
\hline MPQ-13 & 131 & \\
\hline $\begin{array}{l}\text { Pob31(ALM) } \\
\text { HHH-XB }\end{array}$ & 132 & \\
\hline Local & 190.8 & \\
\hline Shaktiman-1 & 211.6 & \\
\hline CM-119 & 302 & \\
\hline Panchaganga & 356 & \\
\hline
\end{tabular}


Most proteomic studies are related to resistance to genus Aspergillus (flavus and parasiticus) [8]; our studies of the content of TI in different varieties of maize resistant (susceptible) to smut and stalk rot showed that the number of TI was increased in resistant varieties and reduced in susceptible varieties, however, there were intermediate variants, called in the literature as "moderately susceptible" [6].

\section{Conclusions}

Based on the importance of presence of proteinase inhibitors in plants, various maize varieties were screened for trypsin inhibitor content. Isolation of TI was performed using an affinity sorbent, trypsin agarose.

Estimating the amount of TI in maize grains can serve as a primary marker of resistance (susceptibility) to fungal pathogens such as smut and stalk rot. The number of TIs is increased in resistant varieties and reduced in susceptible varieties, but there are also intermediate variants — varieties, which are called moderately susceptible in the literature.

\section{Введение}

Растения подвергаются воздействию большого количества инфекционных патогенных грибов. Для кукурузы наиболее распространенными грибковыми патогенами на территории РФ являются пыльная головня, пузырчатая головня, стеблевые гнили, фузариоз. В то время как в странах с жарким и засушливым климатом наиболее распространены патогены рода Aspergillus, воздействие которых наиболее полно изучено.

Так, исследование профилей белка из зерен кукурузы (13 генотипов) выявили конститутивно-выраженный 14 кДа белок, ингибитор трипсина (ТИ), который присутствовал в относительно высоких концентрациях в семи устойчивых к $A$. flavus линиях кукурузы, но в низких концентрациях или отсутствовал вообще в шести чувствительных линиях [1]. 14 кДа ТИ также проявлял антигрибковую активность против других микотоксикогенных видов [2].

Хотя растения не имеют иммунной системы, они используют защитные механизмы, включающие синтез низкомолекулярных соединений, белков и пептидов, имеющих антигрибковую активность. К настоящему времени известно 13 классов антигрибковых белков, среди них можно отметить PR-1 белки, 1,3- $\beta$-глюканазы, хитиназы, хитин-связывающие белки, тауматин подобные белки, дефензины, циклофилин-подобные белки, ингибиторы протеиназ и другие белки [3].

Ингибиторы протеиназ являются составной частью системы защиты от вредителей и болезней [4]. Было показано, что патогенные грибы Fusarium и Helminthosporium выделяют в окружающую среду ферменты, расщепляющие белковые и синтетические субстраты. Разные виды грибов характеризуются неодинаковой активностью внеклеточных протеиназ. Высокое содержание ингибиторов внеклеточных протеиназ патогенных грибов Fusarium и Helminthosporium в семенах гороха, гречихи и кукурузы может служить одним из важных факторов, обеспечивающих устойчивость этих культур к поражению корневыми гнилями [5]. 
Аналогично, было показано, что содержание ИТ 14 кДа в семенах кукурузы коррелирует с устойчивостью сортов к заболеванию A. flavus [3] и, соответственно, накоплению афлатоксина.

ИТ из кукурузы 14 кДа, как было показано, помимо трипсин-ингибирующей активности, обладает активностью альфа-амилазы, и, будучи добавленным в питательную среду, он подавлял прорастание конидий и рост гиф фитопатогенов Aspergillus flavus, Asp. paprasiticus, F. moniliforme, а также проявлял антигрибковую активность против других микотоксикогенных видов [2, 6].

Нами была предпринята экспериментальная работа по исследованию содержания ИТ 14 кДа в образцах кукурузы с заведомо известными свойствами, устойчивости или чувствительности к грибковым патогенам, таким как пыльная головня (возбудитель - Sphacelotheca reiliana), пузырчатая головня (возбудитель болезни Ustilago maydis, U. zeae) и стеблевые гнили кукурузы (возбудитель - гриб Fusarium moniliforme).

\section{Материалы и методы}

Объект исследования. Сорта кукурузы с известными свойствами устойчивости (чувствительности) к грибковым патогенам (пыльная головня, пузырчатая головня, стеблевые гнили) были предоставлены из ВНИИ кукурузы г. Пятигорск. Были исследованы 6 сортов, устойчивых к грибковым инфекциям и 12 сортов, чувствительных к грибковым патогенам.

Подготовка образцов. Семена размалывали, каждый образец кукурузы (10 г) экстрагировали 20 мл 0,2 M раствора $\mathrm{NaCl}$, перемешивали 2,5 ч, затем фильтровали, получали примерно по 15 мл экстракта. К каждому образцу добавляли по 6 г сульфата аммония (60\% насыщения), оставляли в холодильнике на ночь на 18 ч. Затем центрифугировали 10 мин, осадок растворяли в 5 мл буфера $(20$ мМ трис-HCl, 0,15 M NaCl, pH 6,8). Использовали для нанесения на трипсин-агарозу или на ВЭЖХ.

Аффинная хроматография на трипсин-агарозе. В качестве метода выделения был выбран аффинный сорбент - трипсин-агароза [7]. Трипсин-агароза получена иммобилизацией ТPCK-трипсина на $\mathrm{BrCN}$-агарозе.

Для количественной оценки метода использовали стандартный образец 14 кДа ТИ, 200 мкг в 1 мл уравновешивающего буфера.

Образцы по 1,2 мл каждого экстракта наносили на колонку с трипсин-агарозой (4 мл) со скоростью 0,5 мл/мин. После промывки уравновешивающим буфером (10 мМ трис- $\mathrm{HCl}, 0,3 \mathrm{M} \mathrm{NaCl}, \mathrm{pH} 7,0)$ проводили элюцию 0,15 М раствором уксусной кислоты.

ВЭЖХ (гидрофобная хроматография). Анализ образцов проводили на колонке RP-304 (250x4,6) Bio Rad. Использовали следующие условия: 3' - 0\% $\mathrm{CH}_{3} \mathrm{CN} ; 40^{\prime}-100 \% \mathrm{CH}_{3} \mathrm{CN} ; 50^{\prime}-100 \% \mathrm{CH}_{3} \mathrm{CN}, 65^{\prime}-0 \% \mathrm{CH}_{3} \mathrm{CN}$.

200 мкг 14 кДа ТИ предварительно использовали в качестве стандарта.

Электрофорез в ПААГ. SDS-PAGE электрофорез в 15\% геле использовали для анализа образцов. 


\section{Результаты}

Исследовано 6 устойчивых к пузырчатой головне и пыльной головне и 12 сортов, неустойчивых к пузырчатой головне, пыльной головне и стеблевым гнилям. Данные образцы зерен кукурузы с заведомо известными свойствами устойчивости (чувствительности) к таким грибковым патогенам были предоставлены из ВНИИ кукурузы г. Пятигорск.

Площади пиков, полученных в результате хроматографии на трипсин-агарозе, рассчитывались математическими методами. Количество 14 кДа ТИ определяли на основании калибровки, для этого использовали образец, содержащий 200 мкг ТИ (рис. 1).

Типичная картина хроматографии экстрактов зерен кукурузы на трипсин-агарозе приведена на рис. 2.

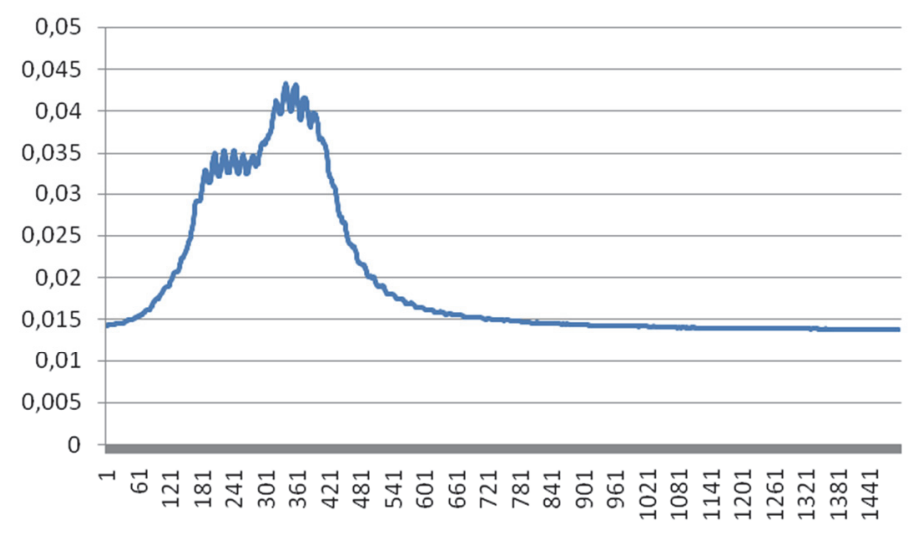

Рис. 1. Стандартная кривая хроматографии с трипсин-агарозы. В данном случае нанесено 200 мкг 14 кДа ТИ для калибровки

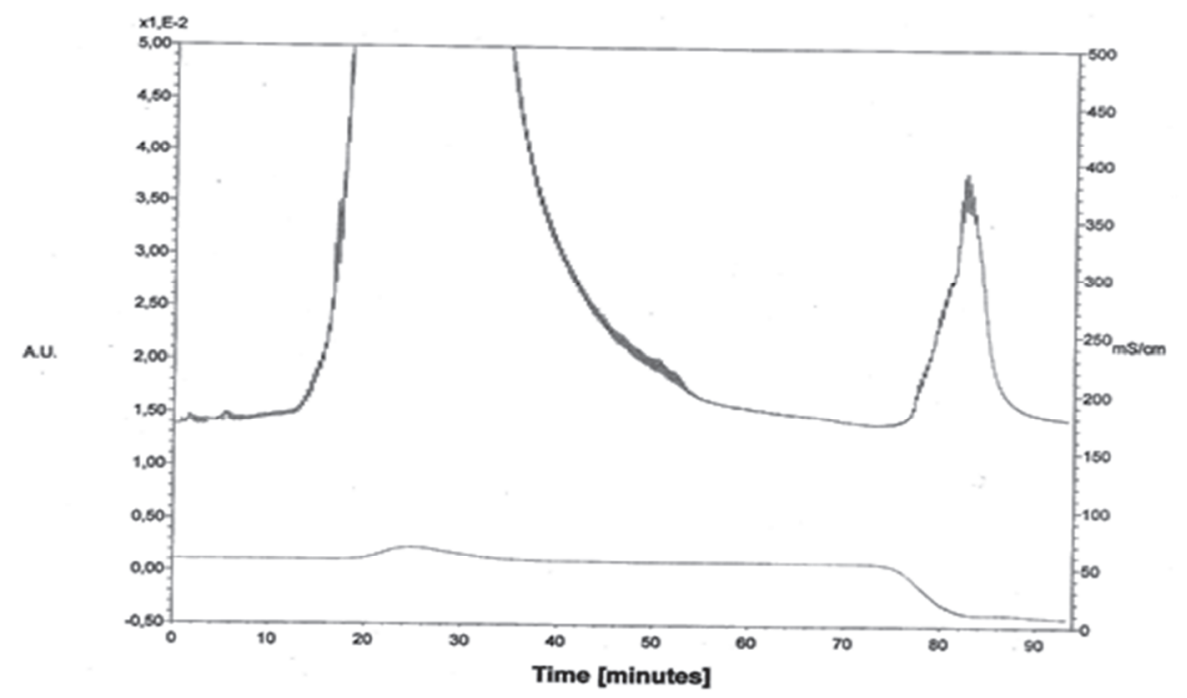

Рис. 2. Типичная кривая хроматографии экстракта зерен кукурузы на трипсин-агарозе: второй пик - элюция ТИ 


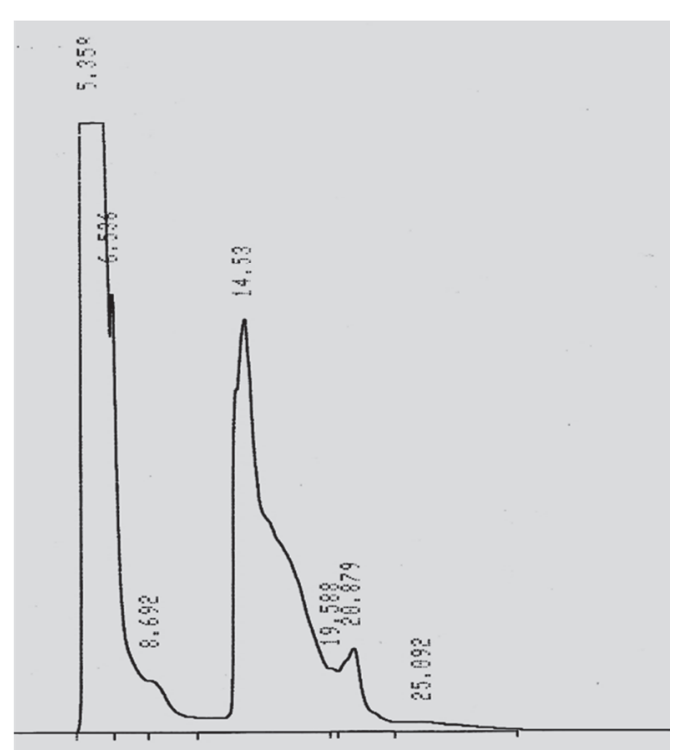

Рис. 3. Типичный профиль элюции экстракта зерен кукурузы на ВЭЖХ

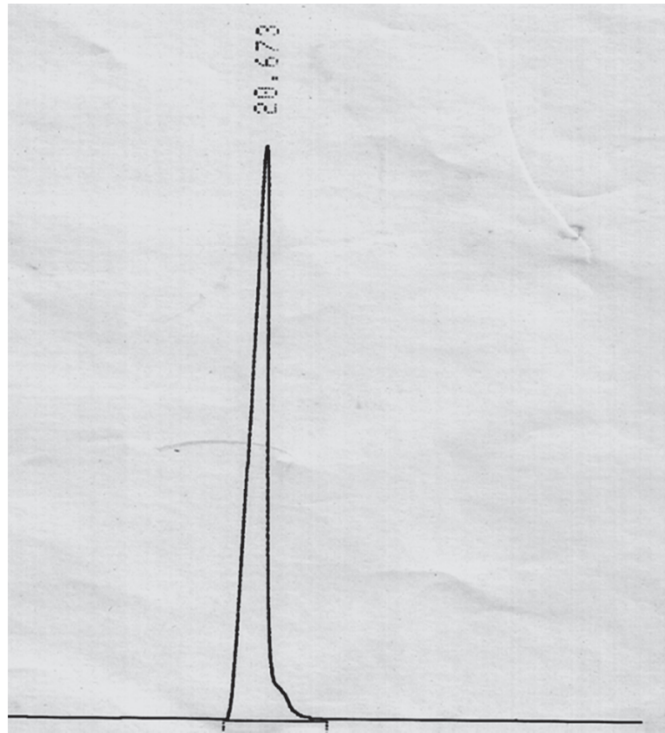

Рис. 4. 14 кДа ТИ в качестве стандарта при ВЭЖХ (200 мкг)

Методом ВЭЖХ были исследованы 4 экстракта разных сортов кукурузы (рис. 3, 4). Были получены следующие результаты:

1-й образец - 4,14\% 14 кДа ТИ (устойчив к пыльной головне, R);

2-й образец — 0,09\% 14 кДа ТИ (чувствителен к пыльной головне, S);

3 -й образец - 3,40\% 14 кДа ТИ (устойчив к пузырчатой головне, R);

4-й образец - 3,60\% 14 кДа ТИ (чувствителен к пузырчатой головне, S).

В дальнейшем был проведен анализ экстрактов зерен разных сортов кукурузы ( $\mathrm{R}$ - устойчивые сорта, S - чувствительные) с использованием аффинной хроматографии на трипсин-агарозе (табл. 1). Было исследовано еще 18 образцов. Для калибровки использовали стандартный образец, содержащий 200 мкг 14 кДа ТИ.

Результаты скрининга сортов кукурузы по количеству 14 кДа ТИ

Таблица 1

\begin{tabular}{|c|c|c|}
\hline Площадь пика элюции & $\begin{array}{c}\text { Рассчитанное количество ТИ } \\
\text { на } 1 \text { г зерен кукурузы }\end{array}$ & $\begin{array}{c}\text { Устойчивость к грибковым } \\
\text { заболеваниям }\end{array}$ \\
\hline 11,3 & 290 МКГ & R пуз гол (580/14) \\
\hline 6,85 & 174 МКг & VR пыльн гол (4716/11) \\
\hline 8,94 & 228 МКг & R пуз гол (3867/11) \\
\hline 13,59 & 347 МКг & R пуз гол (3941/11) \\
\hline 6,3 & 162 мКг & VR пыльн гол (1358/12) \\
\hline 10,9 & 278 МКг & VR пыльн гол (4683/11) \\
\hline 3,29 & 84 МКГ & S пуз гол, стебл гн (2617/09) \\
\hline 4,53 & 115 МКГ & S стебл гн 2597/09 \\
\hline 3,59 & 86 МКГ & S пыльн гол П2/27 2013 г \\
\hline 6,35 & 162 мКг & S пыльн гол (3398/14) \\
\hline 5,83 & 149 мКг & S стебл гнили (2613/09) \\
\hline 7,73 & 197 мКг & S пуз гол (2599/09) \\
\hline 7,6 & 190 мКг & S пуз гол (2075/12) \\
\hline 8,09 & 200 МКг & S пуз гол (2613/09) \\
\hline 5,8 & 140 мКг & S пуз гол (1200/13) \\
\hline 5,5 & 132 мкг & S пуз гол (3358/14) \\
\hline 5,7 & 138 мКг & S пуз гол (1506/14) \\
\hline 7,7 & 190 МКГ & S пуз гол $(605 / 12)$ \\
\hline 7,83 & 200 МКг & ТИ, стандартный образец \\
\hline
\end{tabular}




\section{Обсуждение результатов}

Ранее [1], при исследовании экстрактов зерен кукурузы (13 генотипов) было показано присутствие конститутивного 14 кДа ТИ на относительно высоком уровне концентрации в семи устойчивых к A. flavus сортах кукурузы, но в шести чувствительных сортах ТИ присутствовал в низкой концентрации или отсутствовал вовсе.

Механизм действия ТИ против грибкового роста может быть частично обусловлен ингибированием грибковой амилазы, приводящим к ограничению доступа A. flavus к простым сахарам [5], необходимым не только для роста патогенных грибов, но и для производства ими токсинов. ТИ также продемонстрировал противогрибковую активность и в отношении других микотоксигенных видов [2].

В [6] исследовалось содержание ТИ в разных сортах индийской кукурузы, устойчивых и чувствительных к A. Parasiticus, данные приведены в табл. 2.

Протеомный анализ белков зародышей пшеницы и белков эндосперма сортов кукурузы, устойчивых и чувствительных к Aspergillus flavus, разделенных методом двумерного электрофореза (2 D PAGE), показал, что имеется еще 5 конституитивных маркерных белков, а именно: запасающие белки (глобулин 1 и глобулин 2), белки позднего эмбриогенеза (LEA), белки, связанные с засухой (LEA3 и LEA14) или осмотическим стрессом (WSI18 и альдозоредуктаза) и белки, связанные с тепловым стрессом (HSP16.9). Альдозоредуктазная активность, измеряемая у резистентных и восприимчивых генотипов до и после заражения, свидетельствует о важности конститутивных уровней этого фермента для устойчивости [7].

Таблица 2

\section{Скрининг сортов индийской кукурузы}

стойчивых и чувствительных к A. parasiticus, на содержание ти [6]

\begin{tabular}{|c|c|c|}
\hline Сорт & $\begin{array}{c}\text { Концентрация ингибитора трипсина } \\
\text { в индийских сортах кукурузы }\end{array}$ & $\begin{array}{c}\text { Чувствительность } \\
\text { к A. parasiticus infections }\end{array}$ \\
\hline LM-6 & 242.2 & \multirow{4}{*}{ Устойчивые } \\
\hline $\mathrm{P}(\mathrm{Y}) \mathrm{S}-8-185-6-\mathrm{B} 8 \mathrm{~B}$ & 258 & \\
\hline GY-37-1-328 & 420 & \\
\hline CML-142 & $421-2$ & \\
\hline CML-176 & 90 & \multirow{6}{*}{ Чувствительные } \\
\hline Pob-24-FSRS-C-1 & 90 & \\
\hline Hyd-9745 & 132 & \\
\hline Maduri & 134 & \\
\hline CML-185 & 158 & \\
\hline CML-430 & 188 & \\
\hline CML-291 & 266 & \multirow{10}{*}{ Относительно устойчивые } \\
\hline CML-161 & 36 & \\
\hline African tail & 130 & \\
\hline CML-150 & 130 & \\
\hline MPQ-13 & 131 & \\
\hline $\begin{array}{l}\text { Pob31(ALM) } \\
\mathrm{HHH}-\mathrm{XB}\end{array}$ & 132 & \\
\hline Local & 190.8 & \\
\hline Shaktiman-1 & 211.6 & \\
\hline CM-119 & 302 & \\
\hline Panchaganga & 356 & \\
\hline
\end{tabular}


Большинство протеомных исследований связано с изучением устойчивости к роду Aspergillus (flavus и parasiticus) [8]; проведенные нами исследования содержания ТИ в разных сортах кукурузы, устойчивых (чувствительных) к пыльной головне, пузырчатой головне, стеблевым гнилям показали, что количество ТИ повышено в устойчивых сортах и понижено в чувствительных, однако имеются и промежуточные варианты, в литературе такие сорта названы «умеренно чувствительными» [6].

\section{Выводы}

Исходя из важности присутствия ингибиторов протеиназ в растениях предприняли скрининг разных сортов кукурузы на содержание ингибитора трипсина. Выделение ТИ производили с использованием аффинного сорбента - трипсинагарозы.

Оценка количества ТИ в зернах кукурузы может служить первичным маркером устойчивости (чувствительности) к грибковым патогенам, таким как пыльная головня, пузырчатая головня и стеблевые гнили. Количество ТИ повышено в устойчивых сортах и снижено в чувствительных, однако имеются и промежуточные варианты - сорта, в литературе называемые умеренно чувствительными.

\section{References}

1. Chen ZY, Brown RL, Lax AR, Guo BZ, Cleveland TE, Russin JS. Resistance to Aspergillus flavus in corn kernels is associated with a 14-kDa protein. Phytopathology. 1998; 88(4):276281. doi: 10.1094/PHYTO.1998.88.4.276

2. Chen ZY, Brown RL, Lax AR, Cleveland TE, Russin JS. Inhibition of plant-pathogenic fungi by a corn trypsin inhibitor overexpressed in Escherichia coli. Appl Environ Microbiol. 1999; 65(3): $1320-1324$.

3. Selitrennikoff CP. Antifungal proteins. Appl Environ Microbiol, 2001; 67(7):2883-2894. doi: 10.1128/AEM.67.7.2883-2894.2001

4. Zaynutdinova GF. Belkovye ingibitory ekzogennykh proteinaz v tkanyakh rastenii i ikh fiziologicheskaya rol' [Protein inhibitors of exogenous proteinases in plant tissues and their physiological role]. [Dissertation] Ufa; 2001. (In Russ).

5. Chen ZY, Brown RL, Russin JS, Lax AR, Cleveland TE. A corn trypsin inhibitor with antifungal activity inhibits Aspergillus flavus $\alpha$-amylase. Phytopathology. 1999; 89:902 - 907. doi: 10.1094/PHYTO.1999.89.10.902

6. Hajare SS, Hajare SN, Sharma A. Screening of Indian corn varieties for aflatoxin resistance. BARC News Letter, Founder's Day Special Issue. 2006; (273):218-230.

7. Lei MG, Reeck GR. Combined use of trypsin-agarose affinity chromatography and reversed phase high-performance liquid chromatography for the purification of single-chain protease inhibitor from corn seeds. Journal of Chromatography. 1986; 363(2):315-321. doi: 10.1016/S0021-9673(01)83751-1

8. Chen ZY, Brown RL, Damann KE, Cleveland TE. Proteomics analysis of kernel embryo and endosperm proteins of corn genotypes resistant or susceptible to Aspergillus flavus infection. In: Robens J, Cary JW, Campbell BC. (eds.) Proceedings of the USDA-ARS Aflatoxin Elimination Workshop held at Yosemite. 2000. p. 88.

9. Chen ZY, Brown RL, Damann KE, Cleveland TE. Identification of unique or elevated levels of kernel proteins in aflatoxin-resistant maize genotypes through proteome analysis. Phytopathology. 2002; 92(10):1084-1094. doi: 10.1094/PHYTO.2002.92.10.1084

10. Mosolov VV, Valueva TA. Proteinase inhibitors and their function in plants: a review. Applied Biochemistry and Microbiology. 2005; 41(3):227-246. doi: 10.1007/s10438-005-0040-6 


\title{
Библиографический список
}

1. Chen Z.-Y., Brown R. L., Lax A.R., Guo B.Z., Cleveland T.E., Russin J.S. Resistance to Aspergillus flavus in corn kernels is associated with a 14-kDa Protein // Phytopathology. 1998. Vol. 88. No. 4. P. 276-281. doi: 10.1094/PHYTO.1998.88.4.276

2. Chen Z-Y., Brown R.L., Lax A.R., Cleveland T.E., Russin J.S. Inhibition of plant-pathogenic fungi by a corn trypsin inhibitor overexpressed in Escherichia coli // Appl. Environ. Microbiol. 1999. No. 65. P. $1320-1324$.

3. Selitrennikoff C.P. Antifungal proteins // Appl. Environ. Microbiol. 2001. Vol. 67. No 7. P. 2883-2894. doi: 10.1128/AEM.67.7.2883-2894.2001

4. Зайнутдинова Г.Ф. Белковые ингибиторы экзогенных протеиназ в тканях растений и их физиологическая роль: автореф. дис. ... канд. биол. наук. Уфа, 2001.

5. Chen Z-Y., Brown R.L., Russin J.S., Lax A.R., Cleveland T.E. A corn trypsin inhibitor with antifungal activity inhibits Aspergillus flavus $\alpha$-amylase // Phytopathology. 1999. No 89. P. 902 907. doi: 10.1094/PHYTO.1999.89.10.902

6. Hajare S.S., Hajare S.N., Sharma A. Screening of indian corn varieties for aflatoxin resistance // Founder's day. 2006. No. 273. P. 218-230.

7. Lei M.-G., Reeck G.R. Combined use of trypsin-agarose affinity chromatography and reversed phase high-performance liquid chromatography for the purification of single-chain protease inhibitor from corn seeds // J. Chrom. 1986. No. 363. P. 315-321. doi: 10.1016/S00219673(01)83751-1

8. Chen Z-Y., Brown R.L., Damann K.E., Cleveland T.E. Proteomics analysis of kernel embryo and endosperm proteins of corn genotypes resistant or susceptible to Aspergillus flavus infection // Proceedings of the USDA-ARS Aflatoxin Elimination Workshop held at Yosemite / eds Robens J., Cary J.W., Campbell B.C. CA, 2000. P. 88.

9. Chen Z-Y., Brown R.L., Damann K.E., Cleveland T.E. Identification of unique or elevated levels of kernel proteins in aflatoxin-resistant maize genotypes through proteome analysis // Phytopathology. 2002. No. 92. P. 1084-1094. doi: 10.1094/PHYTO.2002.92.10.1084

10. Mosolov V.V., Valueva T.A. Proteinase inhibitors and their function in plants: review // Appl Biochtv Microbiol. 2005. No 41. P. 227-246. doi: 10.1007/s10438-005-0040-6

\begin{abstract}
About the authors:
Shekhvatova Galina Vladimirovna - Senior Researcher, Research and Production Company Gamma, Pushchino, Russian Federation, 142290; e-mail: shgal06@gmail.com

Ashin Viktor Vasilievich - Candidate of Biological sciences, Junior Researcher, Laboratory of Adaptation of Microorganisms, Skryabin Institute of Biochemistry and Physiology of Microorganisms, 5 Nauki avenue, Pushchino, Russian Federation, 142290; e-mail: ashin@ibpm.pushchino.ru

Sotchenko Elena Fedorovna - Candidate of Biological sciences, leading researcher, Department of Selection for immunity, Russian Research Institute of Corn, 14-B Ermolova st., Pyatigorsk, 357528, Russian Federation; e-mail: elena.minenkova@list.ru
\end{abstract}

\section{Об авторах:}

Шехватова Галина Владимировна - старший научный сотрудник, Научно-производственная фирма «Гамма», Российская Федерация, 142290, г. Пущино; e-mail: shgal06@gmail.com

Ашин Виктор Васильевич — кандидат биологических наук, младший научный сотрудник лаборатории адаптации микроорганизмов, Институт биохимии и физиологии микроорганизмов им. Г.К. Скрябина, Российская Федерация, 142290, г. Пущино, проспект Науки, д. 5; е -mail: ashin@ibpm.pushchino.ru

Сотченко Елена Федоровна - кандидат биологических наук, ведущий научный сотрудник отдела селекции на иммунитет ФГБНУ Всероссийского научно-исследовательского института кукурузы, Российская Федерация, 357528, г. Пятигорск, ул. Ермолова, 14-Б; e-mail: elena.minenkova@list.ru 